\title{
Refugee Health Education: Evaluating a Community-Based Approach to Empowering Refugee Women in Houston, Texas
}

\author{
Elizabeth Leah Frost \\ Christine Markham \\ Andrew Springer
}

\begin{abstract}
Although resettlement agencies in the United States assist refugees by offering a variety of local social and health services, refugees are still less likely to access these services. Few studies have evaluated refugee health education interventions focusing on barriers to accessing healthcare and overcoming negative social determinants of health. This study evaluated the feasibility, acceptability, and perceived impact of a yearlong health education intervention to empower Burmese refugee women living in Houston, Texas. The intervention included workshops, community excursions, question and answer (Q\&A) sessions, and home visits. The evaluation was a formative qualitative study including interviews with Burmese refugee women who participated in the intervention and local resettlement agency caseworkers. Qualitative content analysis guided the data analysis and was conducted to identify categories and emergent themes. Key findings indicated that motivation to participate in the intervention was impacted by the women's perceived relevance of health education material to Burmese cultural values and opportunities for hands-on learning to promote self-efficacy. Recommendations for future interventions include the use of community health workers to train refugee health educators, pairing English lessons with health education material to promote development of English language skills, developing teaching materials for refugees with low literacy, establishing bottom-up support from refugee resettlement agencies, and incorporating the social work ecological model to tailor health-focused interventions to the specific needs of the refugee community.
\end{abstract}

Keywords: Refugee health; women's health; health education; program evaluation

In fiscal year 2015, the United States received approximately 70,000 refugees (United States Department of State, 2015), of whom 7,479 refugees were resettled in Texas. Houston received $39 \%$ of the refugees, making it one of the top destinations for refugee resettlement in the U.S. (Montour \& Kazmierski, 2013). Burmese refugees make up the second largest refugee group in Texas (Montour \& Kazmierski, 2013). In Houston, resettlement agencies assist in connecting refugees to various services including food stamps and health insurance, as well as English as a second language (E.S.L.) classes, job development, and linkage to health clinics. Despite local services offered by resettlement agencies, refugees are less likely to access health and social services due to low health literacy, inability to navigate the healthcare system, scheduling challenges, lack of daycare options, language barriers, differing cultural beliefs, and lack of access to experienced interpreters, all of which lead to an overall decline in health (Murray, Mohamed, \&

Elizabeth Frost MSW, MPH is a graduate of University of Houston Graduate College of Social Work and the University of Texas Health Science Center at Houston (UTHealth) School of Public Health, Houston, TX 77030. Christine Markham $\mathrm{PhD}, \mathrm{MA}$ is an Associate Professor, UTHealth School of Public Health, Houston, TX 77030. Andrew Springer, DrPH, MPH is an Associate Professor, UTHealth School of Public Health in Austin, Austin, TX, 78701. 
Ndunduyenge, 2013; Vermette, Shetgiri, Al Zuheiri, \& Flores, 2015).

Key health issues for newly arrived refugees to the U.S. include a high prevalence of musculoskeletal and pain issues, mental health challenges such as depression, anxiety, and posttraumatic stress disorder, and social problems such as isolation, financial challenges, culture shock, and employment difficulties (Eckstein, 2011). For Burmese refugees, infectious diseases such as hepatitis B, HIV and tuberculosis are also prevalent (Montour \& Kazmierski, 2013). Medical screenings in Texas reveal that recently arrived Burmese refugees make up $47 \%$ of newly diagnosed hepatitis B cases and $24 \%$ of newly diagnosed HIV cases among all recently arrived refugees (Montour \& Kazmierski, 2013). Also, 44\% of newly arrived Burmese refugees settling in Texas were found to have a positive tuberculosis skin test (Montour \& Kazmierski, 2013). Poor initial health outcomes for newly arrived refugees often are a result from living in a refugee camp for numerous years before coming to the U.S.

Designed to tackle health disparities within the refugee population, refugee-focused health and social interventions typically center around community capacity-building, developing self-efficacy to navigate the U.S. healthcare system, and encouraging community empowerment (Baird et al., 2015; Glanz, Rimer, \& Viswanath, 2008; Im \& Rosenberg, 2016; Wieland et al., 2012). Despite an important foundation of public health social work research on refugee health education interventions, few interventions designed specifically for Burmese refugees have been implemented, and little to no program evaluations have been conducted to assess the feasibility and acceptability in delivery of these health education interventions for Burmese refugees living in the U.S. (Hartwig \& Mason, 2016; Ornelas et al., 2017; Rowe et al., 2016; Walker, Koh, Wollersheim, \& Liamputtong, 2015).

In responding to the public health needs of the local Burmese refugee community in Houston, Texas, a pilot community-based health education intervention, titled Refugee Women's Health Initiative, was developed in partnership with a local refugee resettlement agency and implemented by two students from The University of Texas Health Science Center in Houston (UTHealth). Focusing on Burmese refugee women, the pilot intervention provided health education and life skills coaching. Empowerment was defined as building knowledge, skills and self-efficacy across a range of health topics related to both preventive behaviors and navigation of the healthcare system. The intervention provided health education via a life skills approach. Workshops focused on real-life applications to practice new skills and improve skills needed to navigate life in the U.S. Workshop topics were identified from focus groups with Burmese refugees and case managers at the resettlement agency over a two-month period prior to the implementation of the intervention. Workshops were held weekly for one year and included presentations and discussions on a range of health topics, dissemination of health education materials, question and answer (Q\&A) sessions with medical providers, and excursions to promote community exploration. A workshop, excursion, or Q\&A session was planned weekly for the duration of one year. The hour-long workshops were held in a classroom space offered by the resettlement agency with a Burmese interpreter to assist with communication. Home visits were completed twice a month by the intervention team to build rapport with the refugee women. Table 1 provides a summary of the intervention activities and workshop 
topics identified by the women.

Table 1. Workshop Topics, Excursions, and Q\&A Sessions: April 2014-May 2015

\begin{tabular}{|c|c|c|}
\hline $\begin{array}{l}\text { Workshop Topics } \\
\text { - Cultural Adjustment- Life in the U.S. } \\
\text { - Navigating the Public School System for } \\
\text { Parents } \\
\text { - Nutrition } \\
\text { - Job Development - Where to Start Job Hunting } \\
\text { - Dental Care and Oral Hygiene } \\
\text { - Planned Parenthood - Well Woman Exam \& } \\
\text { Family Planning } \\
\text { - Personal Hygiene } \\
\text { - Budgeting Skill Building and Financial Advice } \\
\text { - Substance Abuse and Domestic Violence } \\
\text { - Obesity and Diabetes Prevention } \\
\text { - How to Become a Community Health Worker } \\
\text { - Photo Voice } \\
\text { - Ophthalmology Vision Screening } \\
\text { - Self-esteem, Self-care, and Goal-building }\end{array}$ & $\begin{array}{l}\text { Excursions } \\
\text { - Zumba in park } \\
\text { - Grocery store } \\
\text { visit } \\
\text { - Family trip to } \\
\text { beach } \\
\text { - Children's } \\
\text { museum } \\
\text { - Houston Zoo } \\
\text { - Health fair } \\
\text { - Art museum } \\
\text { - Houston } \\
\text { Medical Center }\end{array}$ & $\begin{array}{l}\text { Q\&A Sessions } \\
\text { - OB/Gynecology } \\
\text { - Pediatrician } \\
\text { - Psychiatrist }\end{array}$ \\
\hline
\end{tabular}

The priority population of the pilot intervention was Burmese-speaking refugee women enrolled in services at the local resettlement agency. Since participation in health education interventions is typically low in minority populations (Mirza et al., 2014; Zanchetta \& Pourselami, 2009), and given the pilot nature of this intervention, there were no restrictions on ethnicity. While Burmese refugees from all ethnic backgrounds were invited to participate, due to funding restrictions, only a Burmese-speaking interpreter was available to assist with the focus group, workshops, and all other activities. As such, only women who were comfortable speaking Burmese attended. Burmese refugee women were specifically invited to participate because of their central role in influencing health outcomes of the family. This includes their important role in managing childcare, and making health decisions for their children and families. Likewise, refugee women are an at-risk priority population because they are typically more isolated, have limited English skills, and feel unsure about their future (Walker et al., 2015). Recruitment for the pilot intervention was facilitated through the case managers from the resettlement agency. Case managers contacted all Burmese refugee clients who were enrolled in services at the agency to provide information about the focus group and future workshops. A total of thirty-eight Burmese refugee women participated in the intervention activities from April 2014-May 2015.

This study was a process evaluation of the Refugee Women's Health Initiative that had the following objectives: 1) To assess the feasibility, acceptability, and initial impact on health knowledge and self-efficacy of the refugee women and resettlement agency staff, 2) To understand process-related aspects of the intervention including knowledge, perceived benefits and implementation barriers, 3) To assess feasibility for future implementation of this health education initiative on a larger scale, and 4) To contribute to the growing public 
health social work literature on interventions for Burmese refugee communities resettled in the U.S. by providing insights from refugee women and resettlement agency staff on best practices for developing and delivering health education programming for recently resettled refugees.

\section{Methods}

This evaluation study used an exploratory, post hoc, single-group only research design to better understand the delivery and initial impact of health education and health promotion strategies in the refugee communities upon completion of the intervention. The evaluation was formative and qualitative in nature, relying on semi-structured interviews to capture perspectives of the refugee women and resettlement agency staff. The same graduate student from the University of Texas Health Sciences acted as the evaluator and conducted data collection and data analysis. The study was approved by the University of Texas Health Sciences Committee for the Protection of Human Subjects.

\section{Participants}

Only Burmese refugee women who had previously participated in the Refugee Women's Health Initiative intervention were eligible to be part of the evaluation. Participation in the intervention was defined as having attended one or more workshops over the course of the year-long intervention. A total of 38 Burmese refugee women were eligible. With the help of the Burmese interpreter, the evaluator reached out to all eligible participants by phone or home visits to recruit for the evaluation study. A total of 11 Burmese refugee women agreed to participate in the evaluation. Twenty refugee women were lost to follow-up, and seven women were unavailable at the time of the interviews. Of those who were lost to follow-up, five had moved to another state, and 15 had changed cell phone numbers and addresses. Figure 1 provides an outline of the recruitment process.

Figure 1. Recruitment Cascade

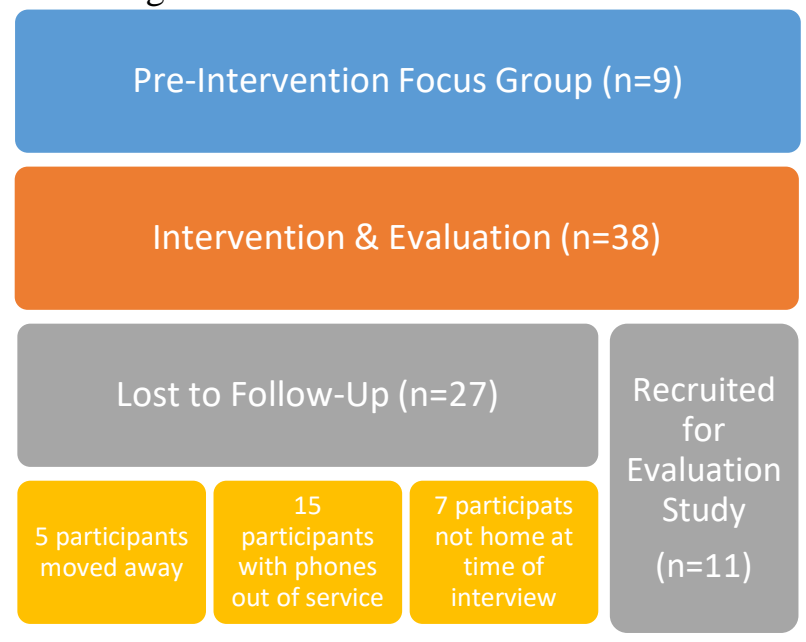

Because of low literacy in both Burmese and English, verbal consent was considered 
most appropriate for the women to fully understand the study and consent process. A scripted consent form was read to the women with the aid of a Burmese interpreter. Participants were informed that participation in the evaluation study would not impact social services received from the refugee resettlement agency. Participants were able to withdraw from the evaluation at any time.

Resettlement agency staff members were selected to participate in the evaluation based on the following criteria: 1) Having worked at the resettlement agency for the past year, and 2) Having had some type of role in the intervention such as acting as the driver in transporting the women to the workshops or providing case management. Permission from the resettlement agency supervisor was obtained for staff to participate in the evaluation. Staff members were provided letters informing them about the study which served as passive consent to participate. Staff were informed that participation would not lead to repercussions in employment status. Confidentiality of information was paramount to protect both the refugee women and staff. Based on the study's criteria for selecting agency staff members, five staff were eligible for interviews and asked to participate.

\section{Data Collection}

A semi-structured interview guide was used to guide interviews with the refugee women. The guide included twelve questions focusing on perceived benefits to participating in the intervention, cultural appropriateness of topics, barriers to attending the workshops or excursions, cues to action for participating, and suggestions for improvement. Interviews were conducted by the evaluator and a native Burmese speaker from the University of Texas Health Sciences who served as the interpreter. Interviews were conducted and audio recorded in the homes of the women with the assistance of the interpreter. In accordance with the preference of the women, interviews with the refugee women included a mixture of individual and group. A brief survey was administered at the time of the interview to collect demographic information. Survey data were verbally collected by the interpreter and recorded on paper by the interviewer.

A separate semi-structured interview guide was administered to the resettlement agency staff and comprised of seven questions addressing the role of the intervention within the resettlement agency, staff's knowledge of the intervention, perceived benefits and barriers of the intervention, and general comments or observations about the overall initiative. All staff interviews were conducted face-to-face with the evaluator and were audio-recorded.

All recorded interview data from both refugees and staff were transcribed verbatim and entered into Atlas.ti for coding (Lapan, Quartaroli, \& Riemer, 2012). Using a native Burmese speaker as an interpreter, the interview questions were translated from English to Burmese so the refugee women would understand the questions being asked. All responses were interpreted back into English and audio recorded. The interviews were then transcribed and an English transcription was used for data analysis.

\section{Analysis}

Interviews were analyzed using conventional qualitative content analysis to generate 
categories inductively from the data. Conventional content analysis is often used when there is limited existing research (Hsieh \& Shannon, 2005), which was the case with existing research on Burmese refugee women. After transcribing the recordings and translating the interviews to English, open coding was performed to examine smaller units of meaning and repeating patterns (Lapan et al., 2012). Themes and codes were shared with the interpreter and colleagues for further contextualization and confirmation of the findings. A coding manual was developed with code names and definitions for assigning codes. A separate coding manual was created for refugee women and staff. The coding manuals evolved throughout the analysis as part of inductive category development. There was no adoption of coding schemes from previous studies (Zhang \& Wildemuth, 2009). Secondary coding established categories to organize key themes, highlight patterns, and make inferences. The interviews with the refugee women were analyzed separately from the interviews with the staff. Quotations from the women were kept in third person to maintain the manner in which the interviews were translated during data collection.

\section{Results}

\section{Characteristics of Participants}

Of the eleven women who agreed to participate in the interviews, six women were interviewed one-on-one, and five were interviewed in groups of two and three. The average age of the women participating in the evaluation was 34 years. On average, the women had spent almost half of their life in a refugee camp and had lived in the United States an average of 3.25 years. A majority (81\%) of the women had a primary school education or less and, of those, $45 \%$ of the women had no education.

\section{Interviews with Refugee Women}

Interview Themes. Four prominent themes were drawn from the interviews with the refugee women: 1) Perceived benefit of participating, 2) Opportunities to practice English, 3) Community as a cultural value, and 4) Family as a cultural value.

For the women attending the intervention, there was a perceived benefit in learning new information that was relevant and useful to their everyday lives. During an interview with a refugee woman who had attended the workshop hosted by Planned Parenthood and the workshop on personal hygiene, the woman spoke at great lengths about the information she learned from the experience. The interpreter translated, "She found the discussion on topics of health, and you know, reproductive health, and personal hygiene was a draw [to attend the workshop]." For this particular woman, there was a perceived benefit in learning about reproductive health and hygiene that attracted her to the workshop. That benefit was a motivator for her to attend. Likewise, the women felt empowered when learning new skills. The interpreter assisted in translating for one woman by stating, "Because she didn't know about family planning before, and then she learned about it in the workshops. So, that's why she liked it. It was useful for her." Empowerment was noted when the women learned a skill that was beneficial in being able to navigate and manage life in the U.S. Some of the women identified the perceived benefit of learning a new skillset as the most important aspect of the intervention, as was noted in the following quote from a woman 
who had attended the Houston Medical Center excursion where she learned to ride the city bus. The interpreter explains, "Her favorite part was the visit to the hospital because she learned how to get there and then how to ask for help at the hospital." Knowledge gained on various health topics and the opportunity to practice a new skillset was a strong motivator for the women to attend the workshops and other activities of the intervention. Overall, there was positive reinforcement associated with attending the intervention. When interviewed, one of the women mentioned knowledge gained as a positive reinforcement to attend the workshops. The interpreter summaries for her, "She said like she didn't know anything about-anything about hygiene, family planning, personal hygiene and family planning or health, but she learned something from this-all these workshops, particularly about the intrauterine device." In general, the women felt they had gained something in return for attending the intervention, whether it be knowledge about a relevant topic or the opportunity to practice certain skillsets.

The opportunity for the women to practice English language skills was a big draw for the women to attend the workshops. Hands-on learning opportunities were embedded in the workshops and community excursions, and workshops were perceived as a safe space to practice the health behavior or life skill while using English. As a result of increased opportunities to practice English and learn vocabulary related to life skills, the women felt more confident in their ability to execute certain life skills such as calling the doctor to make appointments or taking the city bus. A group interview with three women denotes this change in confidence. The interpreter translates for the women, “...now they feel a little bit more confident to call for the appointment or to ask for the appointment [in English]." Using English in the workshops and activities was a strong motivator for some of the women to attend. This was apparent with one woman's quote which was interpreted as, "She thinks it really helped to gain knowledge and also to learn English a little bit more, to talk with friends. That's why she also always liked to participate on all these activities."

The women developed a unique community identity that was formed from a shared experience of participating in the intervention, and it created a foundation for community development and exchange of knowledge and skills. The social aspect was a significant draw for the women to attend the intervention. As was noted from the workshops, a strong sense of community was an observed shared cultural value among the Burmese women, which the intervention helped to nurture and support. The community of women formed through the intervention provided a communication channel for the health education messages. One participant described to the interpreter how she and others would spread the health messages to others in the Houston Burmese refugee community. The interpreter reported that, "They discuss the [home] visits and the workshop at home among each other-they also then talk to other people about the workshop." Relationships were cultivated over the course of the intervention, leading to reciprocal rapport-building among the women. Information was discussed among the women at home and knowledge was passed from woman to woman and from family to family. Health education messages also spread to the larger Burmese refugee community. At one point during an interview, the interpreter stated, "They are Karen not Karenni. But they met with other Karenni women in the workshop and then they learn about them, too." Communication channels were not 
impacted by ethnicity. Health education messages passed between Karen and Karenni Burmese refugees living in Houston.

Family was another strong cultural value identified by the women. Knowledge and skills gained in the workshops were framed in the context of benefiting the family. One woman emphasized the importance of family in the following quote which was translated as, "She felt more confident about healthy behaviors after the workshop, not only for her but also her family and especially for her children." The women wanted their children to become healthier and better adjusted to life in the U.S. The women were more likely to retain information pertaining to the children because of the value placed on family, as was noted in an interview in which the interpreter claimed, "She remembered it because it was the one [topic] she liked to know and it was useful for her, too, because she has kids going to the school. So that is why she still remember." The women's information retention was significantly improved for topics that had a perceived benefit and touched on cultural values such as family or community. During the interviews, the women spoke about the information they were best able to retain, which revolved around topics pertaining to their children's health. The interpreter assisted in translating one woman's views on the workshop topics in a statement, "The most memorable part for her was one of the workshops- a teacher came in and then talked about how to take leave for her children and also how to communicate with the schoolteachers." Linking the intervention to relevant topics and shared cultural values had significant impact on the women's participation in the intervention. As is consistent with best practices in adult health education (National Committee for Health Education, 2016), motivation for the women to attend the workshops was found to be tied to a perceived benefit of attending, opportunities for hands-on learning, and the inclusion of topics that the women felt were applicable to their everyday lives and culturally relevant.

\section{Interviews with Resettlement Agency Staff}

A total of five interviews were conducted with the agency staff. All staff came from the same department within the agency, the long-term case management department. Staff members were in charge of assisting refugee clients who had been in the U.S. for any length of time from three months to five years. None of the staff declined the request for an interview.

\section{Goodness of Fit}

Staff interviews revealed the importance placed on the intervention as being a good fit for the agency, as well as a good fit for the refugee community. Goodness of fit was defined by the agency staff as an intervention that: 1) Has flexibility and the ability to mold to the structure or schedule of the agency, 2) Encourages agency and staff involvement, 3) Fills service gaps and addresses client problems that the agency does not have the capacity to handle, and 4) Does not burden the agency for classroom space, time or financial support. In a comment about program scheduling being a good fit for the agency, a staff member stated, "[Other outside health education programs] kind of have their own kind of timeframe and their own schedule in mind, and they don't really seem to want to work with 
what's best for the entire agency overall, thinking that the only thing we have to do really is like their programming" The emphasis on health education programs being a good fit relates to the work burden placed on case managers at refugee agencies. A case manager who was interviewed reported managing 300 clients who were assigned to his caseload. Refugee case workers oftentimes have extensive caseloads and struggle to provide the indepth attention to all clients. Those with major medical problems often consume the attention of case workers, leaving limited time for interventions aimed at improving the long-term health outcomes in the refugee population. In one particular instance, a staff member claimed, "And so I think that that was great as well that you guys needed less space and much of those women didn't need a lot from us, and I think that was helpful to the staff as well who were overwhelmed with a lot of work already.” The need for programs that counter the heavy work load of the case managers is echoed in the following statement, "It was almost like a breeze honestly compared to others that we've had there, honestly, because-you know-some of the other people we worked with-they really were super kind of needy. Like we had to do all the calling [for program recruitment]. We had to do all the da-da-da-you know. They didn't want to kind of go into the community themselves and do some work. They'd want us to do everything and they would just show up and present." Agency staff who had worked with previous programs that were organized by groups of volunteers were weary of any new projects that would require extra time.

\section{Disconnect}

The heavy work load of the staff at the agency coincided with a certain level of disconnect between the staff and the intervention. The intervention was not fully integrated and adopted into the structure of the resettlement agency. In one interview, a staff member mentioned, "I don't know [about the workshops] because I'm always outside. We provide them transportation. From outside it looks like it goes well. I don't know inside, because I've never been in [the workshops]." Staff who were involved in the intervention were not knowledgeable about some aspects of the program or understood the objectives of the project. Staff involvement in the pilot intervention was limited to providing transportation for the women. None of the agency staff attended a workshop or Q\&A session. Future implementation of the full-scale intervention would ultimately have to depend on external organizers, either social workers or health educators.

\section{Discussion}

This evaluation provides an overview of the feasibility and acceptability of implementing a health education intervention targeted at refugee communities. The findings from the evaluation are consistent with health promotion literature that links peerto-peer learning with community building, increased community participation, and creating a sense of belonging within the refugee population (Im \& Rosenberg, 2016). The strength of the intervention was nesting the health education program within the Burmese refugee community to encourage community members' on-going participation in the development and implementation of the intervention. This was done through an initial focus group with the refugee women to select topics for the workshops, the use of an interpreter from the refugee community, and home visits that allowed an opportunity for 
regular, in-person feedback from the women. Community-building was evident in the development of social networks among the women. Community involvement in the design and implementation was critical for the intervention to be successful. Refugee health literature has established that community-based approaches to implementation and evaluation research are more effective with vulnerable populations such as refugees. Models such as the Community Based Participatory Research (CBPR) and Participatory Action Research (PAR) are recommended strategies (Baird et al., 2015; Balcazar, GarciaIriarte, \& Suarez-Balcazar, 2009; Wieland et al., 2012).

The intervention created a social space for helping refugee women to connect with each other socially and emotionally. Given the multiple health benefits of positive social relationships (Hartwig \& Mason, 2016; Im \& Rosenberg, 2016; Khawaja, White, Schweitzer, \& Greenslade, 2008; Simich, Beiser, Stewart, \& Mwakarimba, 2005; Walker et al., 2015) as well as the adverse health consequences of social isolation (Thoits, 2011; Wilkinson \& Marmot, 2003), public health social work interventions for refugees should be intentional about creating spaces for their participants to get to know each other and to develop social relationships and support. Connections the refugee women make with each other may be even more important than the specific lifestyle skills the program aims to deliver.

The most significant barrier to implementing the intervention was lack of buy-in from the resettlement agency. Staff interviews highlighted the importance of the organizational compatibility of the intervention. When examining whether an agency will adopt an intervention, compatibility of the intervention with the overall mission statement and goals of the agency is a fundamental component (Roger, 2003). This study demonstrates that compatibility and agency buy-in were two of the most significant barriers to creating a feasible and sustainable intervention. The intervention had agency buy-in from the leaders of the resettlement agency, but not from the ground workers who oversaw the daily running of the organization. There needed to be leadership from the bottom up, including incorporation of frontline staff in planning the intervention, as recommended by health promotion planning frameworks such as Intervention Mapping (Bartholomew et al., 2016).

It is important to note the low participation in this evaluation ( $\mathrm{n}=11$ out of possible 38 ). This is particularly important due to the fact that actual participation in a specific health promotion intervention is traditionally low among ethno-cultural groups. This is due to difficulty accessing health information, language barriers, and a lack of culturally appropriate or tailored health education material (Mirza et al., 2014; Zanchetta \& Pourselami, 2009). These low participation rates in the refugee health education programs make it difficult for program planners to fully evaluate outcomes and understand the long term impact of refugee-focused programs. As shown from this evaluation of an intervention for refugees, health educators and social workers working with these populations should focus on developing evaluation strategies that are incorporated into the intervention to overcome problems with low attrition. However, few studies have been done to explore secondary migration of refugees within the first three years after initial resettlement in the U.S. In this study, $18 \%$ of the women participating in the intervention had moved away by the time the evaluation activities began. Also, 55\% did not have a phone that was working which could also indicate that they had moved out of the area. Innovative approaches are 
needed to discover various ways of maintaining communication with a vulnerable population such as the refugee communities so that health care professionals can follow up on healthcare needs, and social workers can provide long-term services to this particular population, and evaluate program outcomes. While it may be difficult to analyze long-term impacts of an intervention with the Burmese refugee population due to attrition, short-term outcomes can be assessed by continuous monitoring and evaluation of the intervention.

The implications for social work point to a need for the ecological approach in better understanding the social determinants of health that impact refugee communities (Ostrander, 2017). Integrating the biopsychosocial, cultural and environmental perspectives is an essential skill for social workers, as recognized by the NASW (NASW, 2016). To utilize the ecological perspective, social workers must be able to move away from the traditional division of micro, mezzo and macro practice in order to view the refugee community in context of the diverse components impacting refugee health (GriseOwens, 2014). Likewise, social workers are key components in the resettlement process because of their ability to analyze situations from a wholistic approach, build cross-cultural connections with clients (Russell, 2001), connect refugees to resources or services, and provide emotional support during the resettlement process (Agbenyiga, 2012). Social workers are ideally placed in resettlement agencies and have the needed skills to be able to positively impact health education messaging, reduce the high loss to follow up rates when implementing programs, and improve overall agency buy-in for future health education programs.

Research studies on refugee health have not focused enough on discovering effective methods for interviewing refugee women. This study used mixed interview styles by interviewing the women individually and in small groups. A mixed interview style was chosen based on the idea of being culturally appropriate and attuned to the needs of the women who requested that they be interviewed in groups. There is little to no existing evaluation data available for the Burmese refugee population, and little to no data on the best practices for conducting evaluations for resettled Burmese refugees in the U.S. Hence, future public health social work research should focus on developing best practices for qualitative methods that address cultural sensitivity and research standards when working with the refugee population.

\section{Recommendations}

Public health social work interventions aimed at improving health outcomes for refugee communities in the U.S. may benefit from the following considerations in regards to designing and implementing health-focused public health social work programs:

1) Incorporate the community health worker (CHW) model as a solution to overcome language and cultural barriers. Language and cultural differences act as significant barriers for refugees attempting to access the healthcare system and negatively impact health outcomes (Clark, Gilbert, Rao, \& Kerr, 2014; Morris, Popper, Rodwell, Brodine, \& Brouwer, 2009; Pesata, Pallija, \& Webb, 1999; Sheik-Mohammed, Mcintyre, Wood, Leask, \& Isaacs, 2006). The CHW model takes into consideration cultural values such as social networks and community identity among communities. Furthermore, peer-to-peer 
teaching is an effective approach using cultural values and existing strengths of the community. The CHW model may also act as a method to overcome high attrition rates in refugee-focused interventions by providing the motivation to stay active in a health education intervention. The CHW certification of completion is a tangible goal that in turn can lead to employment in community health clinics. Having tangible goals and motivators such as a certificate of completion for CHW training can prove to be key in the success of refugee participation in future health promotion programs.

2) Pair English language lessons with health education lessons to promote development of language skills in understanding health. English language competency is an essential survival skill for refugees living in the U.S. due to a lack of accessible and available interpreter services. Oftentimes, refugees do not have the medical vocabulary to feel confident interacting with a health provider when describing health concerns or receiving a diagnosis (Murray et al., 2013; Vermette et al., 2015). English lessons intertwined with health education lessons would provide refugees with vocabulary specific to mental, physical, and social health.

3) Develop partnerships with resettlement agencies to establish agency buy-in and support for health education interventions. Participation from the resettlement agencies is crucial to achieve the intended outcomes of any intervention. Development of an intervention for refugees should begin with the staff members and directors of the resettlement agencies acting as stakeholders in planning and implementation which follows best practices of current health promotion program planning models (Bartholomew et al., 2016). The agency can provide significant resources toward the intervention and assist with accessing the refugee population.

4) Incorporate the social work ecological framework in designing future interventions targeted at refugee communities. The use of a multi-dimensional intervention that addresses social determinants of health at each level and works to address those factors has the potential to positively impact health outcomes for refugee communities.

\section{Limitations}

Although this study has a small sample size, the purpose of this study was to examine the feasibility and acceptability of conducting a year-long pilot health education program for the Burmese refugee population, and to understand the perceived benefits and barriers in implementing such a program. The participant's views obtained in the evaluation may not necessarily reflect those of the Burmese refugee community located in other geographic areas. However, this study provides a description of a health education program for refugees that may serve to guide the development of other interventions. Other refugee populations may have varying cultural beliefs, practices, and cultural experiences that were not identified by this study. The study also has limited geographic bounds and may not be applicable to other regions of the U.S. where social services and healthcare access differ. The design of this study does not address outcome data that measures changes in health behavior of the refugee women. Furthermore, data collection relied upon self-reported data and may reflect some level of response bias. 


\section{Conclusion}

The refugee population has often been neglected in health care policies and medical practices. With opportunities in preventive medicine provided by the expansion of the Affordable Care Act, there is a greater need to reach neglected populations to provide preventive care and health education. Unlike other populations, resettled refugees in the U.S. face particular barriers to accessing healthcare or health education programs. Likewise, the refugee population has particular motivation to attend health education programs that must be understood in a larger cultural context. This study provides information on best practices for working alongside refugees in the U.S., and explores various cultural and programmatic components to consider when designing a health education program for refugees who have been resettled in the U.S. Furthermore, the highlighted recommendations in this study demonstrate the need for social workers to

consider the cultural context of the target population as it relates to health-focused social work programs, and the specific programmatic needs of the refugee population in the U.S. Recommendations from this evaluation study were drawn from a pilot intervention. The lessons learned can be transferred to a larger more in-depth intervention and expanded to meet the needs of refugees from other cultural and language backgrounds. While few studies have been conducted to evaluate Burmese refugee health education in the U.S. and examine the best practices in refugee health education, this study provides a foundation for public health social workers to explore critical knowledge missing in immigrant and minority health research.

\section{References}

Agbenyiga, D. L., Barrie, S., Djelaj, V., \& Nawyn, S. J. (2012). Expanding our community: Independent and interdependent factors impacting refugees' successful community resettlement. Advances in Social Work, 13(2), 306-324.

Baird, M. B., Domian, E. W., Mulcahy, E. R., Mabior, R., Jemutai-Tanui, G., \& Filipe, M. K. (2015). Creating a bridge of understanding between two worlds: Communitybased collaborative-action research with Sudanese refugee women. Public Health Nursing, 32, 388-396. doi: https://doi.org/10.1111/phn.12172.

Balcazar, F. E., Garcia-Iriarte, E., \& Suarez-Balcazar, Y. (2009). Participatory action research with Colombian immigrants. Hispanic Journal of Behavioral Sciences, 31(1), 112-127. doi: https://doi.org/10.1177/0739986308327080.

Bartholomew, K. L., Markham, C. M., Ruiter, R. A. C., Fernandez, M. E., Kok, G., \& Parecel, G. S. (2016). Planning health promotion programs: An intervention mapping approach. San Francisco, CA: Jossey-Bass.

Clark, A., Gilbert A., Rao, D., \& Kerr, L. (2014). 'Excuse me, do any of you ladies speak English?' Perspectives of refugee women living in South Australia: Barriers to accessing primary health care and achieving the Quality Use of Medicines. Australian Journal of Primary Health, 20, 92-97. doi: https://doi.org/10.1071/PY11118.

Eckstein, B. (2011). Primary care for refugees. American Family Physician, 83(4), 429- 
436.

Glanz, K., Rimer, B. K., \& Viswanath, K. (2008). Health behavior and health education, theory, research and practice. San Francisco, CA: Jossey-Bass.

Grise-Owens, E., Miller, J. J., \& Owens, L. (2014). Responding to global shifts: Metapractice as a relevant social work practice paradigm. Journal of Teaching in Social Work, 34(1), 46-59. doi: https://doi.org/10.1080/08841233.2013.866614.

Hartwig, K. A., \& Mason, M. (2016). Community gardens for refugees and immigrant communities as a means of health promotion. Journal of Community Health, 41(6), 1153-1159. doi: https://doi.org/10.1007/s10900-016-0195-5.

Hsieh, H. F., \& Shannon, S. E. (2005). Three approaches to qualitative content analysis. Qualitative Health Research, 15(9), 1277-1288. doi: https://doi.org/10.1177/1049732305276687.

Im, H., \& Rosenberg, R. (2016). Building social capital through a peer-led community health workshop: A pilot with the Bhutanese refugee community. Journal of Community Health, 41(3), 509-517. doi: https://doi.org/10.1007/s10900-015-0124-z.

Khawaja, N. G., White, K. M., Schweitzer, R, \& Greenslade, J. (2008). Difficulties and coping strategies of Sudanese refugees: A qualitative approach. Transcultural Psychiatry, 45(3), 489-512. doi: https://doi.org/10.1177/1363461508094678

Lapan, S. D., Quartaroli, M. T., \& Riemer, F. J. (2012). Qualitative research. San Francisco, CA: Jossey-Bass.

Mirza, M., Luna, R., Mathews, B., Hasnain, R., Hebert, E., Niebauer, A., \& Mishra, U. D. (2014). Barriers to healthcare access among refugees with disabilities and chronic health conditions resettled in the US Midwest. Journal of Immigrant Minority Health, 16(4), 733-742. doi: https://doi.org/10.1007/s10903-013-9906-5.

Montour, J., \& Kazmierski, V. (2013). Texas refugee health program-2014 refugee health report. Retrieved from https://www.unthsc.edu/texas-college-of-osteopathicmedicine/wp-content/uploads/sites/9/Refugee-Health-Report-2014.pdf.

Morris, M. D., Popper, S. T., Rodwell T. C., Brodine S. K., \& Brouwer, K. C. (2009). Healthcare barriers of refugees post-resettlement. Journal of Community Health, 34, 529-538. doi: https://doi.org/10.1007/s10900-009-9175-3.

Murray, K. E., Davidson, G. R., \& Schweitzer R. D. (2010). Review of refugee mental health interventions following resettlement: best practices and recommendations. American Journal of Orthopsychiatry, 80(40), 576-585. doi: https://doi.org/10.1111/j.1939-0025.2010.01062.x.

Murray, K., Mohamed, A. S., \& Ndunduyenge, G. (2013). Health and prevention among East African women in the U. S. Journal of Health Care Poor Underserved, 24(1), 233-246. doi: https://doi.org/10.1353/hpu.2013.0029.

National Association for Social Work [NASW]. (2016). NASW standards for social work practice in health care settings. Retrieved from 
https://www.socialworkers.org/LinkClick.aspx?fileticket=fFnsRHX4HE\%3D\&portalid $=0$

National Committee for Health Education. (2016). The health education specialist: A companion guide for professional excellence ( $7^{\text {th }}$ ed.). Whitehall, PA: National Committee for Health Education.

Ornelas, I. J., Ho, K., Jackson, J. C., Moo-Young, J., Le, A. Do, H. H.,...\& Taylor, V. M. (2017). Results from a pilot video intervention to increase cervical cancer screening in refugee women. Health Education Behavior, 0(0), 1-10. doi:

https://doi.org/10.1177/1090198117742153

Ostrander, J., Melville, A., \& Berthold, S. M. (2017). Working With Refugees in the U.S.: Trauma-Informed and Structurally Competent Social Work Approaches. Advances in Social Work, 18(1), 66-79. doi: https://doi.org/10.18060/21282.

Pesata, V., Pallija, G., \& Webb, A. A. (1999). A descriptive study of missed appointments: Families' perceptions of barriers to care. Journal of Pediatric Health Care, 13, 178-182. doi: https://doi.org/10.1016/S0891-5245(99)90037-8.

Roger, E. M. (2003). Diffusion of innovations. London: Free Press.

Rowe, C., Watson-Ormond, R., English, L., Rubesin, H., Marshall, A., Linton, K.,... Eng, E. (2016). Evaluating art therapy to health the effects of trauma among refugee youth: The Burma art therapy program evaluation. Health Promotion Practice, 18(1), 26-33. doi: http://journals.sagepub.com/doi/pdf/10.1177/1524839915626413.

Russell, M. N., \& White, B. (2001). Practice with immigrants and refugees. Journal of Ethnic and Cultural Diversity in Social Work, 9(3-4), 73-92. doi: https://doi.org/10.1300/J051v09n03_04.

Sheikh-Mohammed, M., Mcintyre, C. R., Wood N. J., Leask J., \& Isaacs, D. (2006). Barriers to access to health care for newly resettled sub-Saharan refugees in Australia. Medical Journal of Australia, 185, 594-597.

Simich, L., Beiser, M., Stewart, M., \& Mwakarimba, E. (2005). Providing social support for immigrants and refugees in Canada: Challenges and directions. Journal of Immigrant and Minority Health, 7(4), 259-268. doi: https://doi.org/10.1007/s10903005-5123-1.

Thoits, P. A. (2011). Mechanisms linking social ties and support to physical and mental health. Journal of Health and Social Behavior, 52(2), 145-161. doi: https://doi.org/10.1177/0022146510395592.

United States Department of State. (2015). FY15 Refugee Admissions Statistics. Retrieved from https://2009-2017.state.gov/j/prm/releases/statistics/251285.htm.

Vermette, D., Shetgiri, R., Al Zuheiri, H., \& Flores, G. (2015). Healthcare access for Iraqi refugee children in Texas: Persistent barriers, potential solutions and policy implications. Journal of Immigrant Minority Health, 17, 1526-1536. doi: https://doi.org/10.1007/s10903-014-0110-z 
Walker, R., Koh, L., Wollersheim, D., \& Liamputtong, P. (2015). Social connectedness and mobile phone use among refugee women in Australia. Health and Social Care in the Community, 23(3), 325-336. doi: https://doi.org/10.1111/hsc.12155.

Wieland, M. L., Weis, J. A., Palmer, T., Goodson, M., Loth, S., Omer, F., ... Sia, I. G. (2012). Physical activity and nutrition among immigrant and refugee women: A community-based participatory research approach. Women's Health Issues, 22(2), e225-232. doi: https://doi.org/10.1016/j.whi.2011.10.002.

Wilkinson, R., \& Marmot, M. (Eds.). (2003). The social determinants of health: The solid facts ( $2^{\text {nd }}$ ed.). Copenhagen, Denmark: WHO Europe.

Zanchetta, M. S., \& Poureslami, I. M. (2009). Health literacy within the reality of immigrants' culture and language. Canadian Journal of Public Health in Canada 2006, 97(2), S26-S30.

Zhang, Y., \& Wildemuth, B. M. (Ed.). (2009). Qualitative analysis of content. In Applications of social research methods to questions in Information and Library Science (pp. 1-12). Santa Barbara, CA: Libraries Unlimited.

Author note: Address correspondence to: Elizabeth Frost, MSW, MPH. Graduate of University of Houston Graduate College of Social Work. Houston, TX 77204. 